\title{
Review
}

Qunfeng Zeng* and Zekun Ning

\section{High-temperature tribological properties of diamond-like carbon films: A review}

https://doi.org/10.1515/rams-2021-0028

received December 31, 2020; accepted March 17, 2021

\begin{abstract}
The rapid development of aerospace industry has made more and more machinery parts of equipment working at high temperature. Due to the lubrication failure of lubricating oil and grease at high temperature, solid lubricant coatings are almost the only effective method to achieve super low friction at high temperature. In recent years, the tribological properties of diamondlike carbon (DLC) films have been extensively studied at high temperature. The present study reviews the microstructure of DLC films and the influence of doping different elements on the structure of DLC films. Second, the mechanical properties and thermal stability of pure DLC films and DLC doped with different elements are also described. DLC films have different microstructures and tribological properties by different preparation methods. Finally, the high-temperature lubrication failure mechanism of DLC films and the tribological properties of DLC films when doped with different elements are discussed from the macro and micro perspectives.
\end{abstract}

Keywords: DLC films, high-temperature tribology, doping elements, thermal stability

\section{Introduction}

With the continuous development of aerospace and other fields in recent years, the requirements for high utilization of resources and energy are increasingly urgent. A large number of theoretical studies and experimental practices have shown that high-speed technology is considered

\footnotetext{
* Corresponding author: Qunfeng Zeng, Key Laboratory of Education Ministry for Modern Design and Rotor-Bearing System, Xi'an Jiaotong University, Xi'an 710049, China, e-mail: zengqf1949@gmail.com

Zekun Ning: Key Laboratory of Education Ministry for Modern Design and Rotor-Bearing System, Xi'an Jiaotong University, Xi'an 710049 , China
}

to be an effective way to achieve this goal, which has also spawned the emergence of high-speed or ultra-high-speed advanced machines. However, at the same time, it means that the two surfaces generate a certain amount of heat when relatively sliding occurs because the surface roughness of the material cannot be absolutely flat. The heat generation per unit time is exacerbated under high speed. The resulting problem is the excessively high temperature. For example, the average working temperature of aero engine bearings, high-speed cutting, and hot working molds is $200^{\circ} \mathrm{C}$ or higher [1,2]. At such high temperatures, wear is exacerbated, and liquid lubricants cannot work properly due to decomposition or oxidation, which makes solid-lubricating materials an inevitable choice $[3,4]$.

At present, there are two main types of solid-lubricating materials: solid composite materials based on metal/ceramic and solid-lubricating films/coating materials [5]. Because the coating material does not change the original excellent mechanical properties of the substrate, it has become the focus of current tribology research [6-10]. In recent years, the lubrication technology at high temperature has been extensively studied, and many nanocomposite coatings have shown excellent tribological properties. The low lubricity of these nanocomposite coatings at high temperatures is mostly due to the formation of another different oxide. $\mathrm{Hu}$ et al. [6] prepared a yttria-stabilized zirconia nanocomposite coating composed of silver and molybdenum and measured that the coefficient of friction (CoF) was below 0.4 from 25 to $700^{\circ} \mathrm{C}$. Aouadi et al. studied a two-phase nanocomposite coating composed of silver inclusions in a vanadium nitride matrix (VN/Ag) from 25 to $1,000^{\circ} \mathrm{C}$ and found that the CoF decreases from 0.35 to 0.1 as the temperature increases, which is attributed to the formation of silver vanadate [7]. The high-temperature tribological properties of the adaptive nanocomposite $\mathrm{Mo}_{2} \mathrm{~N} / \mathrm{MoS}_{2} / \mathrm{Ag}$ coating have also been studied by Aouadi et al. [8]. The CoF at $600^{\circ} \mathrm{C}$ is 0.1 , which is caused by the formation of silver molybdate phase and the fracture of weaker $\mathrm{Ag}-\mathrm{O}$ bonds at high temperatures. Stone et al. [9] used a different method to prepare a silver coating on Inconel and found that its CoF can reach $0.06-0.15$ at a 
temperature of $750^{\circ} \mathrm{C}$. This was mainly due to the formation of $\mathrm{AgTaO}_{3}$ at such a temperature. Kong et al. [10] prepared $\mathrm{ZrO}(\mathrm{YO})-\mathrm{Ag}-\mathrm{CaF}-\mathrm{Mo}$ composites by hot pressing and found that the excellent tribological properties at $400^{\circ} \mathrm{C}$ originate from the formation of $\mathrm{CaMoO}_{4}$, which also makes them have good wear resistance. In addition, since the discovery of super low friction performance of $\mathrm{MoS}_{2}$ in the 1990s, many researchers have conducted a variety of super low friction studies, the most representative of which is diamond-like carbon (DLC) films.

DLC films are metastable amorphous materials mainly composed of $\mathrm{sp}^{3}$ hybridized carbon atoms and $\mathrm{sp}^{2}$ hybridized carbon atoms mixed with each other. When the $\mathrm{sp}^{3}$ content is high (generally greater than $70 \%$ ), this is called tetrahedral amorphous carbon (ta-C). If DLC films contain a certain amount of hydrogen, it is called hydrogenated amorphous carbon (a-C:H) or hydrogenated tetrahedral amorphous carbon (ta- $\mathrm{C}: \mathrm{H}$ ). The structure determines that DLC films have high hardness, high wear resistance, and high elastic modulus [11-16], so DLC films are widely concerned. However, at high temperatures, DLC films undergo oxidation, graphitization, dehydrogenation, and lose their lubricating ability, or even peel off from the substrate, which results in the formation of a transfer layer and wear debris on the sliding surfaces of the counterparts $[3,17]$. Above $300^{\circ} \mathrm{C}$, DLC films are peeled off quickly due to shortened wear lives [18-20]. Unlike most of the aforementioned nanocomposite coatings, the low friction performance of many materials at high temperature is more due to the formation of their oxides, while the low friction of DLC at high temperatures is more due to graphitization. From the perspective of corrosion, Staszewska-Samson and Scendo [21] and Scendo and Staszewska-Samson [22] studied DLC films deposited by plasma vapor deposition on S355 steel and found that the corrosion resistance of DLC began to decline at $400^{\circ} \mathrm{C}$, but DLC completely lost its protective function at $800^{\circ} \mathrm{C}$. From the perspective of structure origin, Wang et al. [23] explored the structural changes of DLC at high temperature and found that high temperature promotes graphitization and enhances the formation of graphene nanoscroll. They found that when the temperature was $150^{\circ} \mathrm{C}$, spherical shape graphene nanoscrolls appear in debris. A delicate balance was established between graphitization and nanocrimping, which reduced $\mathrm{CoF}$ to 0.012 . When the temperature continued to rise to $200^{\circ} \mathrm{C}$, this balance was disrupted and led to an increase in CoF. From the view of molecular dynamics simulation, Wang et al. [24] simulated the high-temperature friction performance of $\mathrm{DLC} / \mathrm{Al}$ and found that $\mathrm{CoF}$ did not change significantly before $300^{\circ} \mathrm{C}$, and $\mathrm{CoF}$ showed a mountain- shaped change tread when the temperature rose above $300^{\circ} \mathrm{C}$. The simulation results showed that at $300-500^{\circ} \mathrm{C}$, interfacial $\mathrm{C}-\mathrm{O}$ and $\mathrm{C}-\mathrm{Al}$ bonds between two substrates are formed during friction, leading to a high CoF. At $500-700^{\circ} \mathrm{C}$, the graphite surface caused by DLC graphitization inhibited the formation of interface bonds, which led to a decrease in the CoF. In addition, doping elements to improve the high-temperature friction properties of DLC has also been extensively studied [25]. Zhang et al. [26] studied Si-doped DLC films (Si-DLC). It was found that the doping of Si could not only increase the hardness and bond strength but also enhance the thermal stability due to the inhibition of graphitization at high temperature. Besides, the author also attributed the high temperature and low friction of Si-DLC to enhanced thermal stability and formation of a Si-containing lubricant layer on the surfaces of the wear tracks. Grigoriev et al. [27] studied the Ti/W co-doped DLC films on steel and discovered that elements caused a decrease in the $\mathrm{sp}^{3}$ content and formed chemical bonds with carbon atoms, which was good in the decrease of CoF. Jongwannasiri et al. [28] investigated DLC films with fluorine and silicon incorporation and discovered that the addition of Si into DLC films strongly influenced $\mathrm{CoF}$ in ambient air, whereas doping with fluorine only slightly influenced DLC films. In addition, exploring the failure mechanism of DLC films at high temperature also plays an important role in improving high-temperature thermal stabilities of DLC films.

The history of high-temperature friction research of DLC films is shown in Figure 1. The relationship between DLC films and temperature was first investigated by Eridmir et al. [18]. The author deposited DLC films on $\mathrm{SiC}$ and compared it with undeposited SiC. The results showed that below $300^{\circ} \mathrm{C}$, DLC films reduced the stable CoF by 3-5 times and the wear rate by $2-3$ orders of magnitude. At the same time, the phenomenon of graphitization and shedding of DLC films at high temperature has also been verified. In 2006, Cemin et al. [29] introduced a Si-containing intermediate layer between the steel substrate and DLC films, and the formation of $\mathrm{Si}-\mathrm{C}$ bonds improved the adhesion in anticipation of improving the mechanical properties at high temperatures. In addition to the introduction of the intermediate layer, the $\mathrm{Cu} / \mathrm{Cr}$-DLC are prepared by Sun et al. [30] through doping $\mathrm{Cu}$ and $\mathrm{Cr}$ has better bond strength than pure DLC films, and the wear rate was significantly reduced above $150^{\circ} \mathrm{C}$. Meanwhile, the researcher also verified that $\mathrm{Cr}$ was a key element for reducing friction. In 2020, Rodriguez et al. [31] mixed Si-DLC with different contents of $\mathrm{Cr}$ and found that $\mathrm{CoF}$ can reach an ultralow friction of $0.009 \pm 0.002$ after using alumina as a 


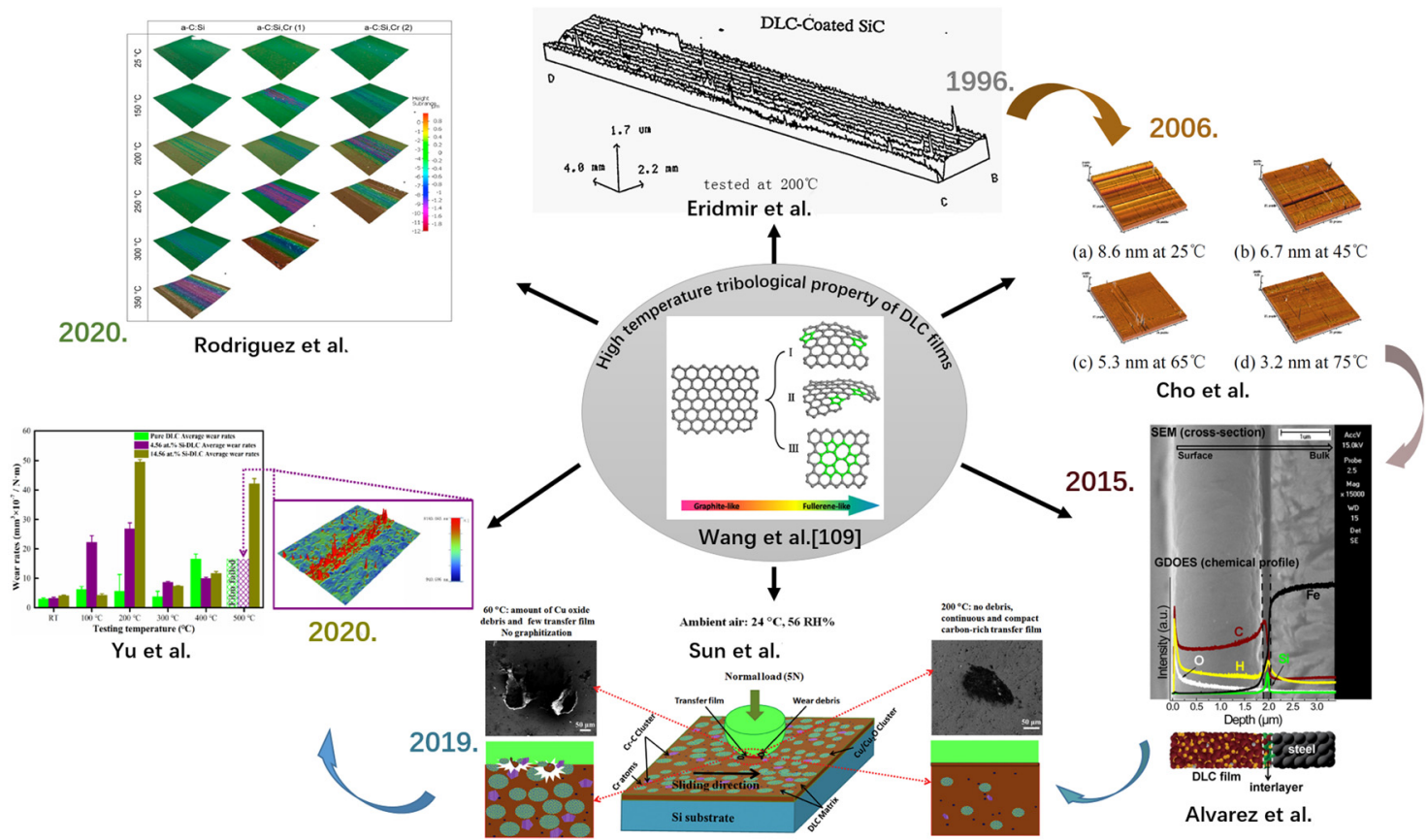

Figure 1: The reading map of DLC films at high temperatures.

counter material at $150^{\circ} \mathrm{C}$. Unfortunately, wear rate at the high temperature has declined. So far, the research on DLC films has been very in-depth, but how to achieve DLC films with low friction at high temperature while maintaining good mechanical properties has not yet been resolved. Based on this point, this article mainly has addressed the related research in recent years from the thermal stability and the high-temperature friction behaviors of DLC films, and then prospects the practical application of DLC films and the subsequent research directions.

\section{High-temperature thermal stability of DLC films}

As a metastable amorphous structure, the existence of $\mathrm{sp}^{2}$ and $\mathrm{sp}^{3}$ bonds in the DLC films changes due to element doping or gradient recombination [32]. The ratio of $\mathrm{sp}^{3}$ and $\mathrm{sp}^{2}$ bonds is a crucial intrinsic parameter, determining the structure and properties of DLC films $[33,34]$. The structural change affects the thermal stability of DLC films, so that DLC films exhibit different new properties under high temperature or other working conditions [35].

\subsection{Microstructure doped with different elements}

As we all know, the ratio of $\mathrm{sp}^{3} / \mathrm{sp}^{2}$ is a determining characteristic in DLC film properties. More $\mathrm{sp}^{3}$ bonds can reduce the friction of ta-C films [36]. The hardness and adhesion of hydrogenated DLC (a-C:H) films are closely correlated with the ratio of $\mathrm{sp}^{3}$ bonding [37]. For different types of DLC films, the properties change according to $\mathrm{sp}^{3}$ content.

For the pure DLC films, Cho et al. [38] deposited DLC films on p-type Si substrate by radio frequency plasmaenhanced chemical vapor deposition. The worn surfaces became smooth and the $I_{\mathrm{D}} / I_{\mathrm{G}}$ ratio was also increasing slightly with increasing temperature. Robertson [32] classified a-C:H films according to the ratio of $\mathrm{sp}^{3} / \mathrm{sp}^{2}$ and the hydrogen contents and showed that a-C:H films present different mechanical properties due to these parameters. The results show that the structure of DLC films exerts a profound influence on performance. Ishikawa and Choi [39] analyzed the microstructures of a- $\mathrm{C}: \mathrm{H}$ by using Raman spectroscopy. Since hydrogen atoms are included in films, $\mathrm{sp}^{3}$ bonds indicate $\mathrm{C}-\mathrm{H} \mathrm{sp}{ }^{3}$ bonds as well as $\mathrm{C}-\mathrm{C}$ $\mathrm{sp}^{3}$ bonds (the bond stretching of all pairs of $\mathrm{sp}^{2}$ atoms in both rings and chains is shown by the G-peak position [40]). The analysis of Raman spectroscopy showed that the a-C:H film with DLC structure had high $\mathrm{sp}^{3} \mathrm{C}-\mathrm{C}$ bonds 
when the wave number regime was $1,540 \mathrm{~cm}^{-1}$. This means high hardness and maximum film disorder at this regime. Cemin et al. [29] studied the characteristics of DLC films on steel substrates using electrostatic confinement plasma enhanced chemical vapor deposition with Si-based interlayer at different deposition temperatures. The results indicate that the adhesive interlayer chemical structure produced by tetramethylsilane was a non-stoichiometric hydrogenated amorphous silicon carbide alloy $\left(\mathrm{a}-\mathrm{SiC}_{\mathrm{x}}: \mathrm{H}\right)$.

In actual production, automobile engine and other parts often work in high temperature, high load, and other environments [41]. Surface texturing has recently been considered as one of the methods to maintain and enhance the tribological properties of DLC films [42]. Arslan et al. [43] investigated the effect of textures on hydrogenated amorphous carbon $(\mathrm{a}-\mathrm{C}: \mathrm{H})$ films at various temperatures. DLC films were deposited on M2 steel by hybrid magnetron sputtering after surface texturing. Xu et al. [44] observed the structure of the W-DLC films using transmission electron microscope and measured the lattice size to be $3-5 \mathrm{~nm}$. This meant that W-DLC films have typical nanocrystalline/amorphous structure characteristics, which is proved by X-ray spectrum and Shera formula calculations. Wang et al. [24] observed electron micrographs of as-deposited films and resulting wear debris on dual balls at different temperatures. For the Si-DLC films, Yu et al. [45] observed the cross-sectional microstructures and corresponding surface topographies of the films with different $\mathrm{Si}$ concentrations, as shown in Figure 2. The results showed that an approximately $300 \mathrm{~nm}$ thick intermediate layer with a columnar structure was observed. Zhang et al. [26] synthesized Si-doped hydrogenated DLC films with various Si contents and indicated that Si doping leads to an obvious increase in the $\mathrm{sp}^{3} / \mathrm{sp}^{2}$ ratio of DLC films, likely due to preferential substitution of the $\mathrm{sp}^{2}$-hybridized carbon atoms by the silicon atoms and augmentation of the number of $\mathrm{sp}^{3}$ sites. Si incorporation into DLC films led to an increase in the number of $\mathrm{sp}^{3}$ sites and thus the formation of more $\mathrm{sp}^{3}$-bonded carbon, stabilizing the structure, which in turn inhibited graphitization of the films at an elevated temperature.

In addition to non-metal elements, the structure of DLC films is also affected by metal element doping. Zhang et al. [46] prepared the Ti-DLC films on 316L steel. The results indicated that Ti-DLC films not only show a uniform color on the substrate but also has the lowest surface roughness $\left(R_{\mathrm{a}}\right)$ and root mean square roughness $\left(R_{\mathrm{q}}\right)$ among the three films. Sun et al. [47] studied the microstructure of $\mathrm{Ni}$ and $\mathrm{B}$ co-doped DLC films. The results conveyed that the Ni/B-DLC films were hydrogenated amorphous carbon films. The prominent mulberry-like structure of the carbon-based films is replaced by a compact and uniform granular structure due to the co-doping of Ni and B.

\subsection{Mechanical properties}

As we all know, the graphitization is proportional to temperature. Graphitization not only leads to a decrease in CoF but also means a decrease in hardness [48]. Cho et al. [38] measured the surface hardness to verify the changed properties. The composite hardness of sliding surface was decreased with increasing temperature due to thermal softening. In addition, hydrogenated amorphous carbon (a-C:H) films have been attracting attention due to their outstanding mechanical properties, such as high hardness, low CoF, and high wear resistance. Choi et al. [49] measured surface roughness, $R_{\mathrm{a}}$, of the a-C:H films using atomic force microscopy and showed that the $R_{\mathrm{a}}$ of all a-C:H films were less than $0.7 \mathrm{~nm}\left(R_{\mathrm{a}}\right.$ of silicon water: $0.17 \mathrm{~nm}$ ). A large number of $\mathrm{C}-\mathrm{C} \mathrm{sp} \mathrm{sp}^{3}$ bonds in DLC-structured $\mathrm{a}-\mathrm{C}: \mathrm{H}$ films are responsible for the high hardness (i.e., high shear strength) and thus the high CoF. Jongwannasiri [50] measured the wear rate of DLC films under dry air and relative humidity environment.

The doping of elements also has a great influence on the hardness of DLC films. By comparing the surface Rockwell indentation morphology of DLC films and W-DLC films, it is found that W-DLC has fewer cracks and less peeling. The results show that the hardness of W-DLC films has been greatly improved. In terms of wear resistance, the wear resistance of W-DLC films continues to decrease with the increase in ambient temperature. Within $200^{\circ} \mathrm{C}$, the wear rate of the film samples can be as low as $1.09 \times 10^{-6} \mathrm{~mm}^{3} /(\mathrm{Nm})$. In the range of $300-400^{\circ} \mathrm{C}$, the wear rate of DLC films rises to $9.43 \times$ $10^{-6} \mathrm{~mm}^{3} /(\mathrm{N} \mathrm{m})$, and when the temperature rises to $500^{\circ} \mathrm{C}$, the wear rate of the film rises to $1.38 \times$ $10^{-5} \mathrm{~mm}^{3} /(\mathrm{N} \mathrm{m})$ [44]. Zhang et al. [47] measured the microhardness of Ni-DLC and Ni/B-DLC, respectively. The high microhardness was not only related to the content of $\mathrm{sp}^{3}$ hybridization for Ni/B-DLC films but also had a part relationship with the formation of $\mathrm{B}_{4} \mathrm{C}$. Deng et al. [51] prepared the a-C:H and Si-DLC films using microwave sheath voltage combination plasma deposition and tested their hardness at elevated annealing temperature. The results indicate that the hardness of the films decreases with the increase in the annealing temperature, and the hardness of a-C:H films decreases beginning at a lower 

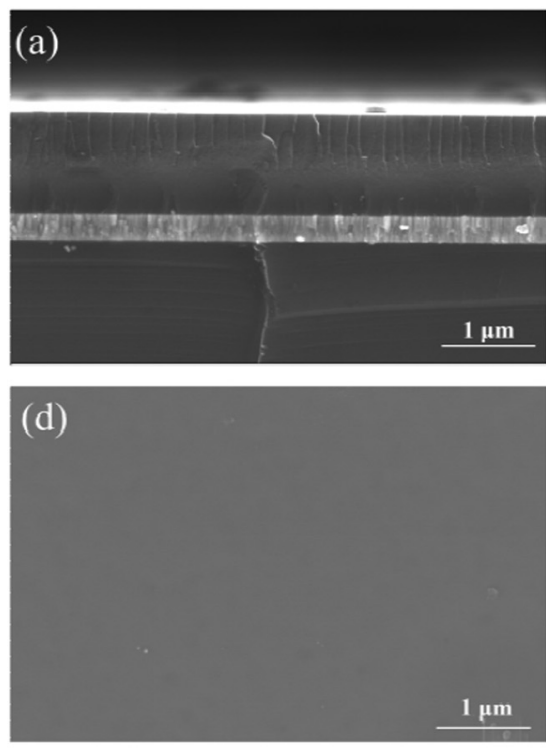
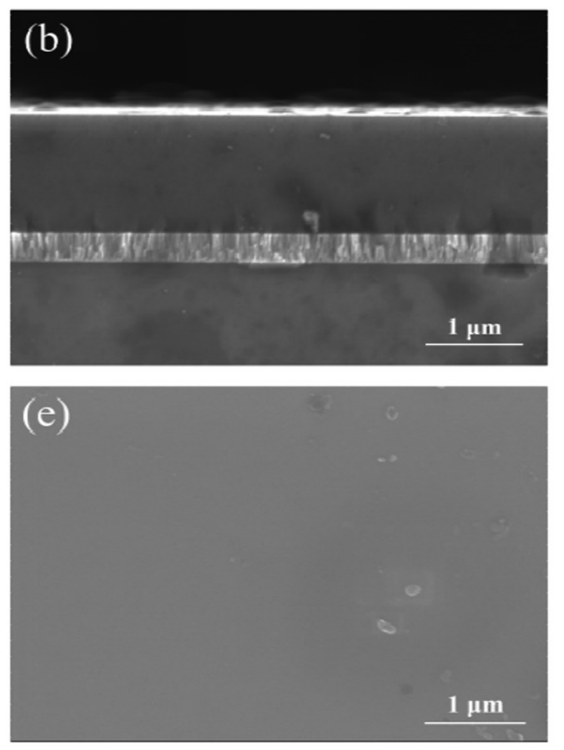
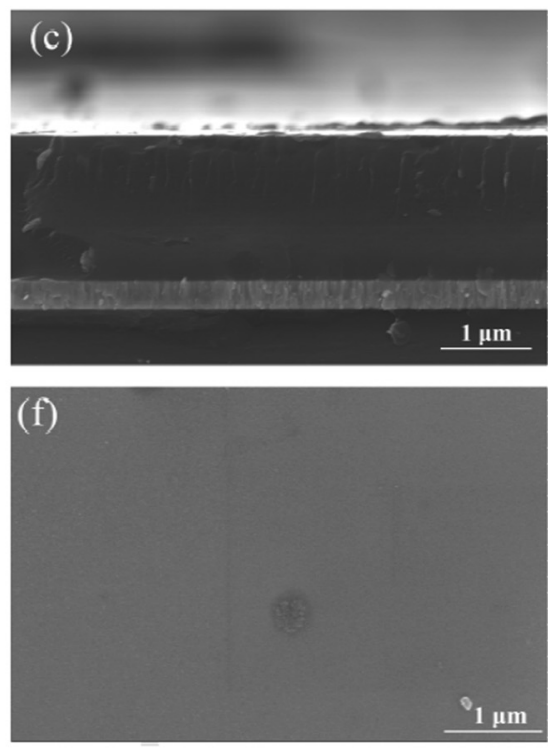

Figure 2: Cross-sectional and planar-view field emission scanning electron microscope images of pure DLC films (a and d), 4.56 at\% Si-DLC films (b and e), and 14.56 at\% Si-DLC films (c and f) [45].

temperature than does that of Si-DLC. For the pure DLC films, the wear rates keep low values below $400^{\circ} \mathrm{C}$. However, at the testing temperature of $500^{\circ} \mathrm{C}$, the pure DLC films have been completely oxidized and disappeared. The wear rate of $4.56 \mathrm{at} \%$ Si-DLC films is $3.2 \times 10^{-7} \mathrm{~mm}^{3} /$ $\mathrm{N} \mathrm{m}$ at room temperature (RT). Since the wear trajectory is convex rather than concave, the wear rate tested at $500^{\circ} \mathrm{C}$ is not shown. It looks like a new layer $\left(\mathrm{SiO}_{X}\right)$ has formed during the friction process. At RT, it is reported that increasing or reducing the adhesion force is considered to be an effective method to improve corrosion resistance properties [52-54]. Zhang et al. [55] fabricated F and Si co-doped DLC films on TC4 Ti alloy substrates using a plane hollow cathode plasma-enhanced chemical vapor deposition technique, which aims at improving the corrosion resistance. Casero et al. [56] declared that the resistance to corrosion of graphene oxide is good to that of graphene, which is attributed to the effect of the $\mathrm{C}-\mathrm{OH}$, $\mathrm{C}-\mathrm{O}$, and $\mathrm{O}=\mathrm{C}=\mathrm{O}$ groups.

In summary, it is easy to find that the structural and mechanical properties of the DLC films change due to the different doping elements. Second, the use of different preparation methods or different preparation parameters affects the mechanism of DLC films.

\subsection{Thermal stability}

It is reported that the thermal degradation caused by graphitization and hydrogen loss at an elevated temperature limits the working temperature of the hydrogen-incorporated DLC films, the tribological properties of which are strongly sensitive to the testing atmosphere [57].

Cemin et al. [58] prepared a silicon interlayer at a deposition temperature range from 300 to $600^{\circ} \mathrm{C}$, then found that the interlayer containing fewer hydrogen and silicon atoms at higher deposition temperatures can enhance the critical load value found for a-C:H film delamination. In addition, with a longer deposition time, the interlayer contains fewer carbon atoms. When the $\mathrm{a}-\mathrm{SiC}_{x}: \mathrm{H}$ intermediate layer is deposited for 5-10 min, the critical load value of the a-C: $\mathrm{H}$ film layering is reduced.

Generally speaking, in order to improve the durability of DLC films on the tribological applications at high temperature, few micrometers of the film thickness are adequate [59]. However, in these cases, greater compression inherent stress is generated, which promotes the failure of the film adhesion and peeling from the substrate surface $[60,61]$. In particular, when DLC films are deposited on a metal alloy, the low chemical affinity, that is, the poor chemical bonding of DLC films with the substrate, also leads to spontaneous debonding. Therefore, a good film/base bonding force is an effective way to improve the thermal stability of DLC films. Currently, it is an effective method to deposit the interlayer between substrate and DLC films [62]. In particular, the siliconcontaining interlayer is chemically more compatible with the material system studied, i.e., silicon has a chemical affinity with the metal atoms present in the alloy and with the carbon atoms constituting the DLC films. 
The thermal stability of DLC films was investigated by annealing test and the structure was evaluated by measuring the Raman spectra. Deng et al. [51] determined the Raman spectra of a-C:H and Si-DLC films annealed at different temperatures. Two spilt $D$ peaks and $G$ peaks can be seen in the spectrum of DLC films before and after annealing test. The $I_{\mathrm{D}} / I_{\mathrm{G}}$ ratio increases and the Gpeak position shifts to higher wavenumber. These results indicate an increase in the number of graphite nanocrystallites per unit volume as the annealing temperature increases.

Element doping can form stable chemical bonds and improve thermal stability. For instance, the improved fracture resistance of the SiCN films stems from the formation of triple $\mathrm{C} \equiv \mathrm{N}$ bonds for the as-deposited films [31]. It is reported that doping Si into the DLC films is a useful approach to improve the thermal stability [63]. This way can not only play an important role in reducing the internal stress of the films [64] but also form $\mathrm{sp}^{3}$ hybridization with $\mathrm{C}$ atoms [65]. Silicon has been reported to have an effect on the residual stresses of the films [66] and reduce the hardness up to a certain silicon content threshold in films without hydrogenated precursors [67]. Voevodin et al. [68] investigated the thermal stability of the pure DLC and Si-DLC (7.7 at\%) films by performing an annealing test. Pure DLC showed sharper $D$ peaks and the $G$ peak position shifted to a much higher wavenumber as compared to that in the Si-DLC film at the same annealing temperature. The $I_{\mathrm{D}} / I_{\mathrm{G}}$ ratio was obtained by fitting two Gaussian curves and a linear background between 900 and $1,800 \mathrm{~cm}^{-1}$. The addition of Si led to higher thermal and mechanical stability because the Si atoms stabilized the $\mathrm{sp}^{3}$ sites and inhibited graphitization of the films at the elevated temperatures.

It can be seen that the main reason affecting the thermal stability of DLC is the proportion of $\mathrm{sp}^{2}$ and $\mathrm{sp}^{3}$ contained in DLC. This ratio shows a functional relationship with the change in temperature. When the content of $\mathrm{sp}^{3}$ is large, it shows strong wear resistance. As the temperature increases, the content of $\mathrm{sp}^{2}$ gradually increases, and DLC also undergoes graphitization and falls off from the matrix.

\subsection{High-temperature mechanical properties of DLC films}

The friction and mechanical properties of DLC films are affected by the preparation method. DLC films have been synthesized by many techniques, including ion beam deposition, magnetron sputtering, pulsed laser deposition, cathodic arc deposition, plasma-enhanced chemical vapor deposition, and electron cyclotron resonance microwave plasma chemical vapor deposition [68-72]. High power impulse magnetron sputtering (HiPIMS) is an advanced physical vapour deposition technique which allows the deposition of dense and ultra-smooth films by improving $\mathrm{sp}^{3}$ contents [73-75].

Wang et al. [24] studied the mechanical properties of DLC films after friction at different temperatures. The results show that the elastic recovery rate of DLC films can reach $80 \%$ after the friction tests at different temperatures. Temperature does have a certain oxidation effect on DLC films, but in the range of $25-200^{\circ} \mathrm{C}$, the mechanical properties of DLC films are less affected.

Staia et al. [74] tested wear rate of a-C:Cr:Si film against a $\mathrm{Si}_{3} \mathrm{~N}_{4}$ ball at $\mathrm{RT}, 400$, and $450^{\circ} \mathrm{C}$ and illustrated the corresponding cross-section profiles of the wear track. The results showed that the cross-section area of the coating tested at $25^{\circ} \mathrm{C}$ is nearly one order of magnitude less than those corresponding to the samples tested at 400 and $450^{\circ} \mathrm{C}$, respectively, and the coated sample tested at $400^{\circ} \mathrm{C}$ had a wear rate approximately three times higher than that tested at $450^{\circ} \mathrm{C}$. The higher resistance to wear at this higher temperature could be probably attributed to the presence of both $\mathrm{SiC}$ and $\mathrm{CrC}$ nanocrystallites, the latter in a higher amount, formed during deposition, which could eventually have maintained the coating hardness.

In summary, the mechanical properties of DLC films at high temperatures mainly depend on the structure of DLC. Doping with different elements forms different chemical bonds, leading to different binding forces. The introduction of an intermediate layer or the preparation of different gradient composite coatings also causes DLC films to exhibit different mechanical properties at high temperatures.

\section{High-temperature tribological properties of DLC films}

\subsection{Failure mechanisms at high temperatures}

There is still controversy about the failure mechanism of DLC films at high temperatures, but current research mainly focuses on the oxidation, dehydrogenation, and graphitization of DLC films. It is believed that the 
decrease in friction in the range of $0-150^{\circ} \mathrm{C}$ is caused by graphitization. Previous research results also show that the reduction of $\mathrm{CoF}$ is closely related to the ease of graphitization [76]. Zhang et al. [26] believed that the heat generated during the friction process may not be dissipated in time at $200^{\circ} \mathrm{C}$, and the overall temperature of the system is too high to maintain a good structural effect, so the ultra-low friction behavior fails. Lee et al. [77] studied the wear mechanism of ta-C films at elevated temperature. For a-C: $\mathrm{H}$ films, the covalent bond strength of $\mathrm{C}-\mathrm{C}$, $\mathrm{C}-\mathrm{H}$, and $\mathrm{C}=\mathrm{C}$ bonds are 346,411 , and $602 \mathrm{~kJ} / \mathrm{mol}$, respectively [78]. Li et al. [79] believed that the surface oxidation of a-C:H films is caused by friction. Because $\mathrm{C}-\mathrm{C}$ and $\mathrm{C}-\mathrm{H}$ bonds are more susceptible to oxidize than $\mathrm{C}=\mathrm{C}$ bonds, the surface chemical states were changed by friction-induced oxidation of the $\mathrm{a}-\mathrm{C}: \mathrm{H}$ films from $\mathrm{C}-\mathrm{C}$, $\mathrm{C}-\mathrm{H}$ bonds to oxygen-containing groups, which resulted in a higher CoF.

$\mathrm{Xu}$ et al. [44] studied the friction of W-DLC films at different temperatures. There is a significant decrease in the $\mathrm{CoF}$ at $500^{\circ} \mathrm{C}$. The research shows that when the temperature is not too high, the formation of the transfer films on the surface of the friction pair reduces CoF. On the other hand, at $500^{\circ} \mathrm{C}$, the width of the wear scar is still around $2 \mu \mathrm{m}$, but its steady-state $\mathrm{CoF}$ is equivalent to that at RT. This showed that W-DLC films exhibit a different friction mechanism at $500^{\circ} \mathrm{C}$ than at RT. By analyzing the chemical composition of the non-wear area on the surface of the W-DLC films after the friction and wear test and Raman spectroscopy in the temperature range of $25-500^{\circ} \mathrm{C}$, the oxide $\mathrm{WO}_{3}$ besides graphite was discovered.

Wang et al. [24] studied the structure of carbon film at elevated temperature and then divided the influence of temperature carbon film into three stages: (1) at $25-150^{\circ} \mathrm{C}$, the high test temperature leads to the higher degree of graphitization, which promotes the formation of nanoscrolls and reduction of $\mathrm{CoF}$. (2) With the temperature increased to $150^{\circ} \mathrm{C}$, graphitization and crimping achieve the best match, showing the lowest friction coefficients at 0.012 . (3) When the temperature exceeds $150^{\circ} \mathrm{C}$, excessive graphene layers are generated and they cannot crimp in time, which destroys the incommensurate contact and increases the $\mathrm{CoF}$, i.e., the temperature-dependent friction behavior of DLC films is determined by the competition between the thermodynamic of formation graphene sheets and the dynamics of nanoroll crimping.

$\mathrm{Yu}$ et al. [45] investigated lubrication mechanism of Si-DLC films with $\mathrm{W}$ interlayer at $500^{\circ} \mathrm{C}$. It is believed that the mechanism for lowering $\mathrm{CoF}$ at $500^{\circ} \mathrm{C}$ is the synergistic effect of amorphous carbon films and the tungsten interlayer. The Si-doped DLC films undergo graphitization and oxidation. In this process, the original dense films become loose and their mechanical properties deteriorate rapidly. When the $\mathrm{W}$ interlayer is exposed, a part of tungsten is oxidized to form $\mathrm{WO}_{3}$ and $\mathrm{WO}_{2}$ phases, while the other part reacts with the residual $\mathrm{C}$ (or wear debris) to form the WC phase, which are embedded in the thin loose carbon film and provide a low friction coefficient at $500^{\circ} \mathrm{C}$. Zhang et al. [26] believed that the peeling of the Si-DLC films is mainly due to three factors: first, the adhesion strength of the DLC films is enhanced by doping $\mathrm{Si}$, and the delamination of the film during the sliding process is prevented. Second, the thermal stability of the DLC films is improved by silicon doping, graphitization is suppressed at high temperature, and hardness loss is reduced to improve the high-temperature friction performance. Finally, the formation of a silicon-containing oxide layer on the Si-DLC films will result in an additional lubricating effect at high temperatures.

\subsubsection{Influence of substrate}

The tribological properties of DLC films at high temperatures are also affected by the material of the substrate. For example, DLC films deposited on silicon substrates, stainless steel substrates, and cemented carbides exhibit different heat resistance [80]. Kong et al. [81] studied the microstructure and tribological properties of DLC films coated on the marketed YT14 cemented carbide cutting tools, which could still maintain a very low $\mathrm{CoF}$ at a temperature of about $800^{\circ} \mathrm{C}$. The research showed the XRD patterns of DLC films at different temperatures and believed that the transfer of atoms occurred between substrate and the films during the wear process.

\subsubsection{Interlayer}

For DLC films, there is usually an intermediate layer between the films and the substrate to enhance adhesion, especially for the steel substrates. Therefore, after the films are broken, the counterpart first contacts the intermediate layer, and the oxide is generated by the oxidation of the intermediate layer at high temperature in the friction process.

Yu et al. [45] investigated high-temperature tribological properties of Si-DLC films with a W interlayer and discovered that the 4.56 at $\%$ Si-DLC films are greatly improved, which is attributed to the tribochemistry of $\mathrm{W}$ interlayer at $500^{\circ} \mathrm{C}$, which formed a film composed of tungsten oxides and carbide. 
(a)

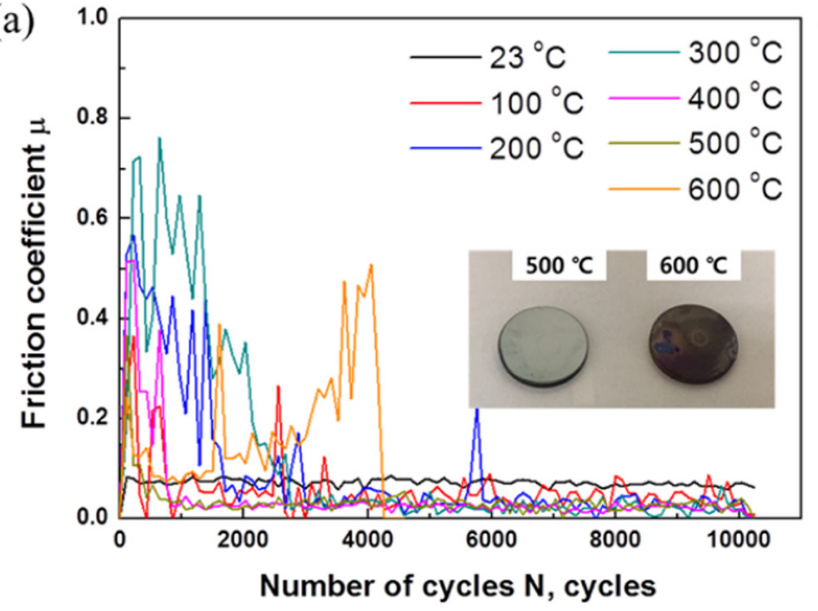

(b)

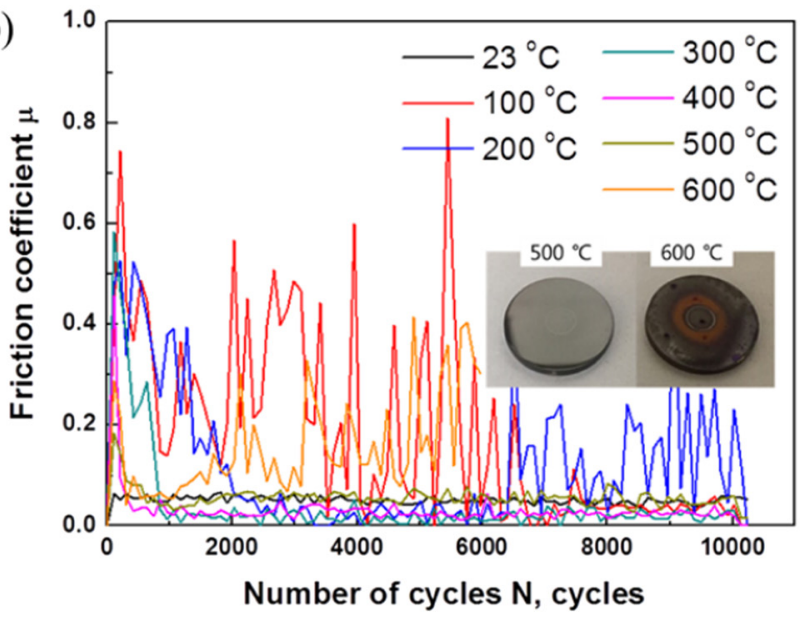

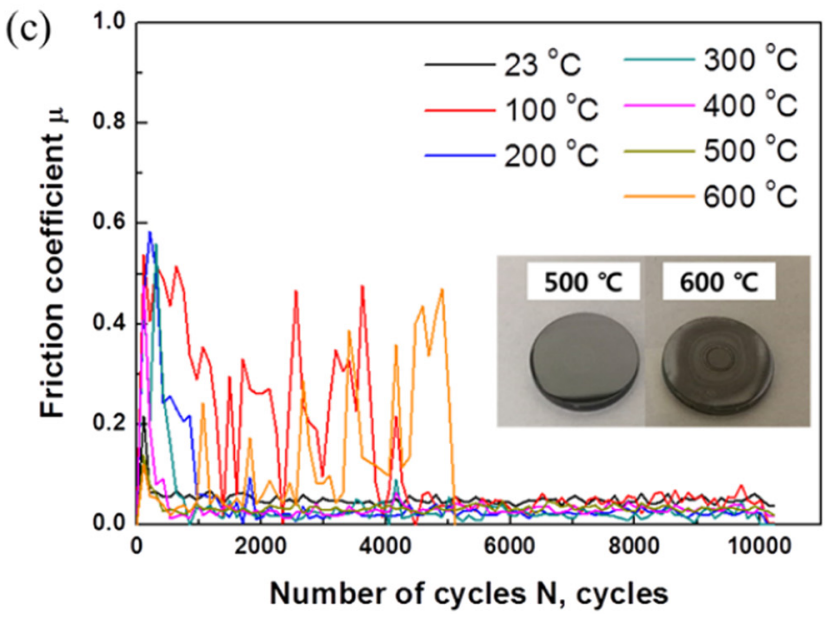

Figure 3: CoF of ta-C coatings fabricated by different substrate biases at (a) $0 \mathrm{~V}$, (b) $-100 \mathrm{~V}$, and (c) $-300 \mathrm{~V}$ as a function of the number of sliding cycles at elevated temperature [77].

\subsection{Effects of deposition parameters and operating environments}

In different working environments, such as substrate bias, circulating gas, and surface texture, DLC films show different friction effects. In previous studies, the deposition parameters, including target power, bias voltage, pressure, and gas flow, were adjusted to investigate the level of influence on the properties of DLC films in order to achieve the optimization.

Lee et al. [77] examined the tribological behavior of $1 \mu \mathrm{m}$ of ta-C coating deposited with different substrate biases of $-0,-100$, and $-300 \mathrm{~V}$ at an elevated temperature of up to $600^{\circ} \mathrm{C}$ (Figure 3). The results show that wear behaviors of $100 \mathrm{~V}$ ta- $\mathrm{C}$ coating show severe wear due to the abrasive particles with highest $\mathrm{sp}^{3}$ content and specific wear rate decreased with increasing substrate bias at 300,400 , and $500^{\circ} \mathrm{C}$. High substrate bias voltage not only produces better adhesion to DLC films but also leads to lower hardness and poor wear resistance. The hardness difference of the DLC layer prepared by Li et al. [82] under the bias voltage of 80 and $160 \mathrm{~V}$ is about $5 \mathrm{GPa}$, so the multilayer DLC films can be prepared by alternating hard and soft DLC monolayers.

Even though the bias voltage has a great influence on the performance of the DLC films, the effect of bias voltage differs because of the difference in composition and structure of DLC films, such as the ratio of $\mathrm{sp}^{3} / \mathrm{sp}^{2}$. Li et al. [82] prepared non-hydrogenated DLC films with various ratios of $\mathrm{sp}^{3} / \mathrm{sp}^{2}$ on cemented carbide YG8 with DC magnetron sputtering technology. Before DLC deposition, a surface etching pretreatment was carried out by mid-frequency magnetron sputtering method, using Ti atoms to improve adhesion strength. The results indicated that the ratio of $\mathrm{sp}^{3} / \mathrm{sp}^{2}$ fluctuated with bias voltage, increasing in the range of 0.74-0.98. The CoF of DLC films against $\mathrm{Si}_{3} \mathrm{~N}_{4}$ increased with increasing ratios of $\mathrm{sp}^{3} / \mathrm{sp}^{2}$, but the friction coefficient against Ti6Al4V decreased. 
At RT, Jongwannasiri [50] investigated DLC films to determine the effects of plasma post-treatment $\left(\mathrm{O}_{2}\right.$ or $\mathrm{CF}_{4}$ ) on friction and wear behaviors under dry air and in a high relative humidity environment. The results showed that the $\mathrm{O}_{2}$ and $\mathrm{CF}_{4}$ plasma treatments both influenced the CoF more when it was measured under dry air than when it was measured in a high relative humidity environment. Sun et al. [30] prepared the $\mathrm{Cu} / \mathrm{Cr}$-DLC films and proposed a simple model of wear mechanism between steel ball and films.

Miyake et al. [83] prepared extremely thin DLC films with various thicknesses, which is deposited using filtered cathodic vacuum arc (FCVA) and plasma chemical vapor deposition (P-CVD) methods. The results show that $\mathrm{CoF}$ depends on temperature for FCVA-DLC and P-CVD-DLC films. The CoF of the FCVA-DLC films was stable and low at RT, after heating at less than $300^{\circ} \mathrm{C}$, whereas the $\mathrm{CoF}$ of the P-CVD-DLC films tended to stay low for more durability test cycles at high temperatures. The researchers believe that the increase in CoF of the FCVA-DLC films at high temperatures was attributed to the removal of the lubricous adsorbed on their surface during sliding at high temperatures. The low CoF of P-CVD-DLC films is attributed to the lubricous layer produced by the tribochemical reactions of the hydrogencontaining P-CVD-DLC films at high temperatures.

For artificial saliva environment, Ding et al. [84] proposed two different theories regarding the friction mechanism in TiDLC films of graphitization and passivation. The former believed that, during the friction and wear test, the flash point temperature can surpass $300^{\circ} \mathrm{C}$, which causes the transition of $\mathrm{sp}^{3}$-bonded $\mathrm{C}$ to $\mathrm{sp}^{2}$-bonded $\mathrm{C}$ in Ti-DLC films. While the latter thought that dangling bonds can adsorb gas or water molecules in the air, which be removed from the surface so that dangling bonds were exposed to air. Exposure of dangling bonds is also why the increase of the CoF of Ti-DLC films.

The deposition temperature also has a great impact on the performance of the DLC films. Sun et al. [30] synthesized the $\mathrm{Cu} / \mathrm{Cr}$ co-doped DLC films deposited at different temperatures using hybrid ion beam deposition system. The results show that even if the increasing temperature increases the internal stress of the $\mathrm{Cu} / \mathrm{Cr}$-DLC films, the hardness and film base bonding force have been greatly improved. Kalin et al. [85] prepared the Ti/ Si-DLC films on the Si substrate using intermediate frequency magnetron sputtering technology. The researchers also found that the migration ability of atoms improves with the increase in deposition temperature, which caused reduction of contents.

The presence of texture also has a great influence on the friction performance of DLC films. Arslan et al. [43] prepared textured and untextured DLC on M2 steel and tested the $\mathrm{CoF}$ at various temperatures $(30,80$, and $125^{\circ} \mathrm{C}$ ). The researchers believed that the reason for the decrease in $\mathrm{CoF}$ of untextured DLC films at 80 and $125^{\circ} \mathrm{C}$ may be due to higher graphitization transformation, while the increase in CoF for untextured DLC films at the later part of friction testing may be due to the coating delamination. In the case of textured DLC films, CoF increases with the increase in temperature, which is different from untextured DLC films. This may be due to the suppression of graphitization by the textures; and lowering of lubricant viscosity with temperature may reduce the lubricant film thickness.

The friction performance of DLC films is closely related to the type of lubricants. Some studies reported positive chemical interaction between DLC coatings and oils and additives $[86,87]$, whereas some found no or negative interaction $[88,89]$. Some antiwear additives, such as ZDDP and MoDTC, could facilitate the slip [90]. Al Mahmud et al. [91] investigated the tribological properties of a-C:H and ta-C DLC films on AISI316 stainless steel at different test temperatures in the presence of commercial lubricating oil.

Tani et al. [90] investigated the low friction mechanism of DLC films heated by laser irradiation in a nitrogen environment. The research showed that CoF unexpectedly dropped significantly at $250^{\circ} \mathrm{C}$, which was attributed to the production of a large amount of hydrocarbons. These hydrocarbons were generated from the heated DLC films and played an important role in decreasing the CoF.

\subsection{Doping elements}

Doping elements has been widely studied as an important way to improve DLC films. The doped DLC films have great changes in mechanical and friction properties. In the current research, the main doping methods can be non-metal doping, metal doping, and element co-doping.

\subsubsection{Non-metal-doped DLC films}

Hydrogen content affects the interaction between lubricant additives and DLC films. Some researchers reported that hydrogen in the matrix has negative effects under lubricated conditions. Amorphous non-hydrogenated (a-C) DLC yields lower CoF than amorphous hydrogenated (a-C:H) DLC under lubricated (engine oil 5W-30, SJ grade) conditions. $\mathrm{Yu}$ et al. [45] measured CoF of 

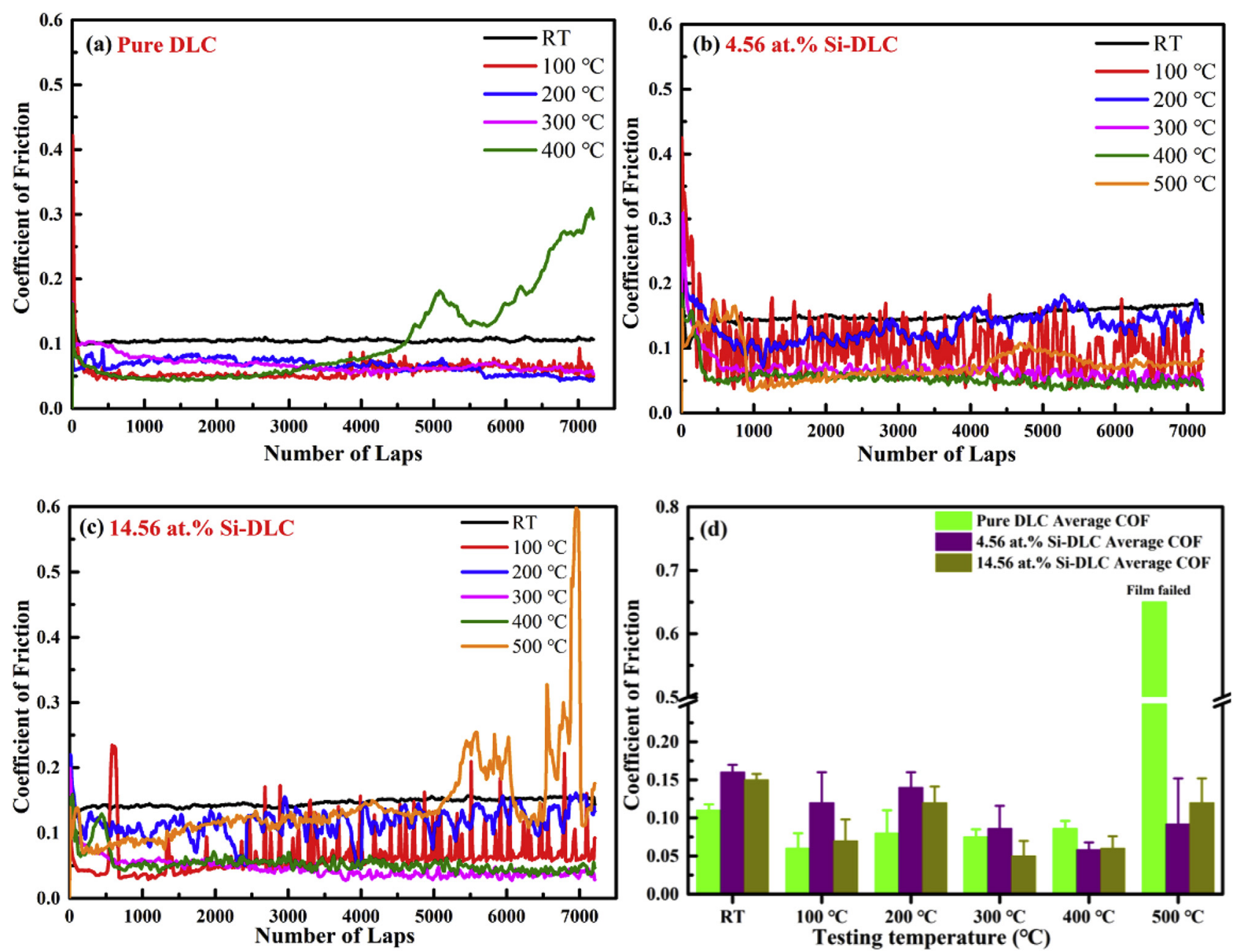

Figure 4: (a) Pure DLC, (b) 4.56 at\% Si, and (c) 14.56 at\% Si. (d) Steady state average CoF as a function of testing temperatures. Error bars are the standard deviations of the steady state values [45].

DLC films with the ball-on-disk method. The minimum value of $\operatorname{CoF}(\mu=0.012)$ is obtained at $150^{\circ} \mathrm{C}$. However, at $200^{\circ} \mathrm{C}$ CoF rapidly increased to about 0.1 after the running-in stage reduced to 0.02 . The researchers believed that this result is related to graphitization.

A lot of research has also been carried out on Sidoped DLC films at high temperature. It is reported that the tribological properties are enhanced by silicon doping at RT and high temperature [92,93], and CoF decreases as the silicon content increases due to the formation of silicon oxide on the sliding surface $[94,95]$. Yang et al. [96] tested CoF of 26 at\% Si-DLC, which is about 0.14 at $400^{\circ} \mathrm{C}$. Bhowmick et al. [97] prepared a-C:H/a-Si:O composite film and measured its $\mathrm{CoF}$ at $400^{\circ} \mathrm{C}$ to be 0.1 . Jantschner et al. [98] studied the effect of temperature on CoF of non-hydrogenated Si-DLC films. The results showed that the formation of $\mathrm{Si}-\mathrm{O}-\mathrm{C}$ bonds at $300^{\circ} \mathrm{C}$ induced an ultra-low $\operatorname{CoF}(<0.02)$. After that, due to the formation of $\mathrm{SiO}_{2}$ oxidized by the $\mathrm{Si}-\mathrm{O}-\mathrm{C}$ bond, the $\mathrm{CoF}$ increases sharply above 0.5 at $500^{\circ} \mathrm{C}$. It seems that the Si-DLC films are difficult to be applied at $500^{\circ} \mathrm{C}$ because of their intrinsic limitations.

Generally, the low friction of Si-DLC films can only be maintained at a temperature below $450^{\circ} \mathrm{C}$ [95-97]. A lot of research (i.e., doping other elements on the basis of SiDLC films) has also been carried out to improve their friction performance at high temperature due to the limitations of pure silicon-doped DLC films. Yu et al. [45] deposited DLC films with different silicon contents combined with $\mathrm{W}$ interlayer. The results showed that the SiDLC films with Si content of 4.56 at $\%$ keep low CoF $(0.2-0.05)$ at high temperature up to $500^{\circ} \mathrm{C}$. The $14.56 \mathrm{at} \%$ Si-DLC films failed at $500^{\circ} \mathrm{C}$ induced by the formation of $\mathrm{SiO}_{2}$. Figure 4 shows $\mathrm{CoF}$ as a function of sliding laps tested at different temperatures for DLC films with different $\mathrm{Si}$ contents. In addition, among the metal dopants, 
chromium is widely known for its formation of carbide nanoparticles in a carbon matrix. Chromium doping is related to reduction in the residual stresses and friction $[99,100]$, while increasing the critical load [101].

\subsubsection{Metal-doped DLC films}

Tungsten, a widely used element, is also doped into DLC films to improve the mechanical and tribological properties. Although the content of tungsten has a small effect on the hardness and elastic modulus of the DLC films, the maximum critical load of the scratch test will appear when the content of tungsten is a certain value [102]. In other words, it has good adhesion between DLC films and the substrate. At the same time, the author also found that the CoF of W-DLC films is smaller, especially under polyalpha olefin (PAO) + thiophosphoric acid amine (T307) salt lubrication. It can be seen that $\mathrm{CoF}$ is relatively stable when the temperature is below $400^{\circ} \mathrm{C}$. W-DLC films can maintain a good anti-friction effect in the temperature range of $25-200^{\circ} \mathrm{C}$, and their $\mathrm{CoF}$ can be kept below 0.1. At $300-400^{\circ} \mathrm{C}$, CoF of W-DLC films fluctuates sharply above 0.3 and almost loses lubrication characteristics. At $500^{\circ} \mathrm{C}$, due to the formation of hightemperature oxidation product $\mathrm{WO}_{3}$, CoF of W-DLC films can reach about 0.15 . It can be seen that the wear rate is proportional to the temperature. Bhowmick et al. [103] studied the W-DLC films and compared the CoF of H-DLC and W-DLC films against $319 \mathrm{Al}$ alloy under ambient air. In this case, CoF of W-DLC films is $25 \%$ lower than that of H-DLC. The researchers believed that the W-doped DLC films have a low and stable CoF, which can be attributed to the fact that the tribofilm is rich in W and S elements. Gharam et al. [104] investigated the tribological behavior of W-DLC against $319 \mathrm{Al}$ at different temperatures. When the temperature is higher than $400^{\circ} \mathrm{C}$, low friction of W-DLC can be attributed to the formation of tungsten oxide $\left(\mathrm{WO}_{3}\right)$.

In addition to the impact of $\mathrm{W}$ doping on the mechanical and friction properties of DLC films, a large number of studies on $\mathrm{Cr}$ doped DLC films have also been carried out. Santiago et al. [105] believed that any chromium addition would have a negative effect on the thermal stability and wear rate according to the Raman spectroscopy results presented in this work. It was suggested that the formation of chromium carbide bonds is responsible for the reduction in both mechanical and wear properties, and that it is only when metallic chromium is distributed along the matrix that the properties are enhanced.
Ti has also been doped into DLC films by researchers to improve their mechanical and friction properties. Zhang et al. [46] compared the mechanical and tribological properties of TiN, TiCN, and Ti-DLC. The results showed that TiCN exhibits a lower CoF because the formation of TiC increases the hardness of the material compared to TiN. The Ti-DLC film shows much lower CoF in dry or wet conditions.

\subsubsection{Metal/non-metal co-doped DLC}

Since single-element doping has a limited influence on DLC films at different temperatures, multiple element doping and gradient layers have been widely concerned. Co-doping of multiple elements is considered to be an effective way to improve the mechanical properties and high-temperature friction properties of carbon films $[100,101]$.

Tomasik [62] investigated the tribo-mechanical properties of a-SiC doping nitrogen and discovered that the best tribo-mechanical performance in terms of high hardness and sufficient level of ductility was observed for the a- $\mathrm{Si}_{0.32} \mathrm{C}_{0.32} \mathrm{~N}_{0.36}$ films. Li et al. [106] prepared W/Ti-DLC films with different $\mathrm{W}$ contents. The results show that DLC films with low $\mathrm{W}$ content exhibited low internal stress, CoF, and wear rate. Zhang et al. [107] studied the W/Ti co-doped DLC films with different Ti contents under PAO, PAO + MoDTC, and PAO + ZDDP lubrication conditions. The results can be summarized that Ti content has little effect on the microstructure and mechanical properties when it is lower than 0.68 at $\%$, but graphitization increases on the W/Ti1.9\%-DLC films, where TiC is detected. On one hand, the addition of MoDTC into PAO can dramatically reduce the friction property of W/Ti-DLC films due to the formation of $\mathrm{MoS}_{2}$ tribofilm and graphitization whereas accelerate wear of film. On the other hand, the wear rates decrease dramatically when the Ti content is higher than 0.68 at $\%$ under PAO + ZDDP lubrication.

Staia et al. [74] investigated CoF of a-C:Cr, Si films deposited on the steel substrate under different temperatures (RT, 400 , and $450^{\circ} \mathrm{C}$, respectively). It can be observed that the rate of change in the value of $\mathrm{CoF}$ at the beginning of the test is high, but much more pronounced in the case of the tests conducted at $400^{\circ} \mathrm{C}$. Rodriguez et al. [31] prepared the chromium, silicon co-doped films deposited using closed-field unbalanced magnetron sputtering and investigated the mechanical and tribological properties of a-C:Cr:Si. Besides, the effect of chromium additions 
on thermal stability of silicon-doped films is also analyzed. The $\mathrm{CoF}$ and specific wear rate were investigated for the same temperatures applied during Raman measurements using an $\mathrm{Al}_{2} \mathrm{O}_{3}$ ball as a counterpart. As the temperature increased, silicon, chromium co-doped films consistently reported a larger specific wear rate with increasing chromium doping having a direct effect. This can be attributed to the formation of alternative bonding, which is related to the presence of chromium. For $\mathrm{Si}$, Cr codoped DLC films, the overall performance has been significantly improved. Santiago et al. [105] believed that the improvement of a-C:Si, $\mathrm{Cr}$ is attributed to its benefit from alternative deposition techniques such as HiPIMS.

\subsection{Multi-layered DLC films}

The performances of DLC films can be changed not only through the co-doping of elements but also the composite gradient layer is also an effective method. The carbon fiber/pyrolytic carbon/silicon carbide $\left(\mathrm{C}_{\mathrm{f}} / \mathrm{SiC}\right)$ composite was prepared by precursor infiltration and pyrolysis [108]. The CoF and microstructure were also investigated by a reciprocating pin-on-disk configuration under dry sliding condition. The researchers believed that the significant decrease in $\mathrm{CoF}$ of $\mathrm{C}_{\mathrm{f}} / \mathrm{SiC}$ was attributed to the increase in carbon content of friction surface, which is caused by the strong fiber-matrix interface and the decrease in matrix strength. Kim and Kim [109] deposited multi-layered DLC films on the AISI steel substrate. The coating consisted of sequentially deposited gradient $\mathrm{Cr} / \mathrm{CrN}$, a-C:H:W, and aC:H layers.

\section{Applications of DLC films at high temperature}

DLC films have become the important coatings to improve energy efficiency in the field of modern industry. In addition, it also has numerous applications, such as in optical, mechanical, electronic, and biomedical fields [110,111].

Nowadays, many materials with special properties are widely used in the field of biomedicine because they can better adapt to the body's environment [112-116]. In the biomedical area, Ti-DLC films are widely used as a coating on artificial joints, because of the complex atmosphere of the human body. Bayón et al. [114] prepared TiDLC films by changing deposition parameters, showing the excellent corrosion response and electrochemical stability at body temperature. Ti addition to a-C:H films resulted in the increased bone cell proliferation and minimized activity of osteoclast-like cell [115]. Bociaga et al. [116] investigated the silver-doped nanocomposite carbon (Ag-DLC) films for biomedical applications. DLC films with various atomic bond structures and compositions are finding places in orthopedic, cardiovascular, and dental applications. Cells grew onto DLC films without any cytotoxicity and inflammation. DLC films in orthopedic applications reduced wear, corrosion, and debris formation. DLC films also reduced thrombogenicity by minimizing the platelet adhesion and activation.

DLC can basically maintain its own properties in a relatively wide temperature range and has a variety of excellent mechanical properties, so it also has a wide range of applications in the industrial field. In a dry and unlubricated environment, an extremely important factor for the applicability of DLC films on components, e.g. in engines, and on tools, is the adhesion [117]. As mentioned above, the introduction of an intermediate layer such as a chromium-containing intermediate layer can form a $\mathrm{Cr}-\mathrm{C}$ bond or prepare a gradient layer, which is of great help to the improvement of adhesion. In the water environment, due to their high chemical stability and wear resistance, DLC films have been used as a solid lubricant in water hydraulic systems, and their working temperature is $20-300^{\circ} \mathrm{C}[118,119]$. In addition, since the silicon devices often exhibit limitations in some environments, for example, it fails at a high temperature, high radiation environment, and chemical erosion. In extreme environments such as $250^{\circ} \mathrm{C}$, DLC films are expected as an alternative material to replace silicon varistors in pressure sensors [120]. However, since the piezoresistive properties of DLC films are far less well-known than Si, further research is necessary to optimize the growth, doping, and patterning of thin films. In the bearing field, repeated start/stop accelerates the failure of the bearing, especially for high-speed gas foil bearings. H-DLC films have been proven to be applicable to foil bearings at RT. In practical applications, it was concluded that the combination of H-DLC foil with $\mathrm{WS}_{2}$ coating could provide excellent performance on tribology [121]. But when the temperature is high, it is difficult to maintain the excellent friction performance at RT. Nevertheless, DLC films still have a wide range of applications in many fields. In recent decades, there has been more and more research on improving DLC films in extreme conditions [122]. We have reason to believe that as an expected material, the improved DLC films are definitely and widely used in the future. 


\section{Summary}

This article reviews the microstructure, mechanical properties, friction behaviors, and engineering applications of DLC films. First, the effect of the doping elements on the microstructure and high-temperature tribological properties of DLC films is addressed. Generally, DLC films undergo the graphitization and dehydrogenation at high temperatures, resulting in the low $\mathrm{CoF}$ and the stable microstructure at about $400^{\circ} \mathrm{C}$. When silicon, fluorine, chromium, tungsten, manganese, titanium, and other elements are doped, the critical failure temperature of DLC films can be greatly changed, up to $800^{\circ} \mathrm{C}$.

Second, the high-temperature tribological properties of DLC films are affected by the preparation methods and the operating environment. This article comprehensively compares the mechanical and tribological properties of DLC films prepared by the physical/chemical vapor deposition technology. Finally, the failure mechanism of DLC films and DLC films doped with different elements, and the hardness and nanoindentation were also affected at high temperature. Therefore, these factors may be considered comprehensively in practical applications in order to achieve excellent tribological properties of DLC films at high temperature.

In future work and research, the influence of the doping elements on the high-temperature tribological properties of DLC films and the microstructure of DLC films are considered, and the film/substrate bonding properties are not ignored.

Acknowledgements: The present work was financially supported by the National Natural Science Foundation of China (51675409), the National Science and Technology Major Project (j2019-IV-0004-0071), and the Natural Science Foundation of Chongqing, China (cstc2019jcyj-msxmX0577).

Funding information: The present work was financially supported by the National Natural Science Foundation of China (51675409), the National Science and Technology Major Project (j2019-IV-0004-0071), and the Natural Science Foundation of Chongqing, China (cstc2019jcyjmsxmX0577).

Author contributions: Qunfeng Zeng: Organization, Investigation, paper-reviewing. Zekun Ning: writing-Original draft preparation, paper-reviewing.

Conflict of interest: Authors state no conflict of interest.

\section{References}

[1] Zhu, S. Y., J. Cheng, Z. H. Qiao, and J. Yang. High temperature solid-lubricating materials: A review. Tribology International, Vol. 133, 2019, pp. 206-223.

[2] Semenov, A. P. Tribology at high temperature. Tribology International, Vol. 28, 1995, pp. 45-50.

[3] Aouadi, S. M., H. Gao, A. Martini, T. W. Scharf, and C. Muratore. Lubricious oxide coatings for extreme temperature applications: A review. Surface and Coatings Technology, Vol. 257, 2014, pp. 266-277.

[4] Franz, R. and C. Mitterer. Vanadium containing self-adaptive lowfriction hard coatings for high-temperature applications: A review. Surface and Coatings Technology, Vol. 228, 2013, pp. 1-13.

[5] Bahce, E. and N. Cakir. Tribological investigation of multilayer $\mathrm{CrN} / \mathrm{CrCN} / \mathrm{TaN}$ films deposited by close field unbalanced magnetron sputtering. Reviews on Advanced Materials Science, Vol. 58, No. 1, 2019, pp. 271-279.

[6] Hu, J. J., C. Muratore, and A. A. Voevodin. Silver diffusion and high-temperature lubrication mechanisms of YSZ-Ag-Mo based nanocomposite coatings. Composites Science and Technology, Vol. 67, No. 3-4, 2007, pp. 336-347.

[7] Aouadi, S. M., D. P. Singh, D. S. Stone, K. Polychronopoulou, F. Nahif, C. Rebholz, et al. Adaptive VN/Ag nanocomposite coatings with lubricious behavior from 25 to 1,000 degrees $C$. Acta Materialia, Vol. 58, No. 16, 2010, pp. 5326-5331.

[8] Aouadi, S. M., Y. Paudel, W. J. Simonson, Q. Ge, P. Kohli, C. Muratore, et al. Tribological investigation of adaptive Mo2N/MoS2/Ag coatings with high sulfur content. Surface and Coatings Technology, Vol. 203, No. 10-11, 2009, pp. 1304-1309.

[9] Stone, D. S., S. Harbin, H. Mohseni, J. E. Mogonye, T. W. Scharf, C. Muratore, et al. Lubricious silver tantalate films for extreme temperature applications. Surface and Coatings Technology, Vol. 217, 2013, pp. 140-146.

[10] Kong, L. Q., S. Y. Zhu, Z. H. Qiao, J. Yang, Q. L. Bi, and W. M. Liu. Effect of Mo and $\mathrm{Ag}$ on the friction and wear behavior of $\mathrm{ZrO}_{2}\left(\mathrm{Y}_{2} \mathrm{O}_{3}\right)-\mathrm{Ag}-\mathrm{CaF}_{2}-\mathrm{Mo}$ composites from $20^{\circ} \mathrm{C}$ to $1,000^{\circ} \mathrm{C}$. Tribology International, Vol. 78, 2014, pp. 7-13.

[11] Beghi, M. G., A. C. Ferrari, K. B. K. Teo, J. Robertson, C. E. Bottani, A. B. Li, et al. Bonding and mechanical properties of ultrathin diamond-like carbon films. Applied Physics Letters, Vol. 81, 2002, pp. 3804-3806.

[12] Balandin, A. A., S. Ghosh, W. Bao, I. Calizo, D. Teweldebrhan, F. Miao, et al. Superior thermal conductivity of single-layer graphene. Nano Letters, Vol. 8, 2008, pp. 902-907.

[13] Novoselov, K. S., A. K. Geim, S. V. Morozov, D. Jiang, Y. Zhang, S. V. Dubonos, et al. Electric field effect in atomically thin carbon films. Science, Vol. 306, 2004, pp. 666-669.

[14] Zeng, Q. F., F. Yu, and G. N. Dong. Superlubricity behaviors of $\mathrm{Si}_{3} \mathrm{~N}_{4} / \mathrm{DLC}$ films under PAO oil with nano boron nitride additive lubrication. Surface and Interface Analysis, Vol. 45, 2013, pp. 1283-1290.

[15] Zeng, Q. F., F. Yu, G. N. Dong, and Y. B. Xie. Mechanism analysis of improved DLC films friction behaviors with liquid sulfidation treatment. Applied Surface Science, Vol. 259, 2012, pp. 83-92. 
[16] Zeng, Q. F., O. Eryilmaz, and A. Erdemir. Analysis of plastic deformation in diamond like carbon films-steel substrate system with tribological tests. Thin Solid Films, Vol. 519, 2011, pp. 3203-3212.

[17] Zeng, Q. F., O. Eryilmaz, and A. Erdemir. Ultralow friction of $\mathrm{ZrO}_{2}$ ball sliding against DLC films under various environments. Applied Science, Vol. 7, 2017, id. 938.

[18] Erdemir, A. and G. R. Fenske. Tribological performance of diamond and diamond like carbon films at elevated temperatures. Tribology Transactions, Vol. 39, 1996, pp. 787-794.

[19] Zeng, Q. F. Thermally induced superlow friction of DLC films in ambient air. High Temperature Materials and Processes, Vol. 37, 2018, pp. 725-731.

[20] Zeng, Q. F., O. Eryilmaz, and A. Erdemir. Superlubricity of the DLC films-related friction system at elevated temperature. RSC Advances, Vol. 5, 2015, pp. 93147-93154.

[21] Staszewska-Samson, K. and M. Scendo. Influence of higher and high temperature on anticorrosive properties of diamond-like carbon coating on S355 steel. Ochrona Przed Korozja, Vol. 62, No. 6, 2019, pp. 197-203.

[22] Scendo, M. and K. Staszewska-Samson. Effect of temperature on anti-corrosive properties of diamond-like carbon coating on S355 steel. Materials, Vol. 12, 1659, No. 10, 2019, id. 1659.

[23] Wang, D., Z. Gong, B. Jiang, G. Yu, G. Liu, and N. Wang. Structure original of temperature depended superlow friction behavior of diamond like carbon. Diamond and Related Materials, Vol. 107, 2020, id. 107880.

[24] Wang, Y., J. Xu, J. Zhang, Q. Chen, Y. Ootani, Y. Higuchi, et al. Tribochemical reactions and graphitization of diamond-like carbon against alumina give volcano-type temperature dependence of friction coefficients: A tight-binding quantum chemical molecular dynamics simulation. Carbon, Vol. 133, 2018, pp. 350-357.

[25] Cobianu, C., N. Dumbravescu, B. C. Serban, O. Buiu, C. Romanitan, F. Comanescu, et al. Sonochemically synthetized ZnO-Graphene nanohybrids and its characterization. Reviews on Advanced Materials Science, Vol. 59, 2020, pp. 176-187.

[26] Zhang, T. F., Z. X. Wan, J. C. Ding, S. Zhang, Q. M. Wang, K. H. Kim. Microstructure and high-temperature tribological properties of Si-doped hydrogenated diamond-like carbon films. Applied Surface Science, Vol. 435, 2018, pp. 963-973.

[27] Grigoriev, S. N., V. Y. Fominski, R. I. Romanov, M. A. Volosova, A. V. Shelyakov. Effect of energy fluence and Ti/W codeposition on the structural, mechanical and tribological characteristics of diamond-like carbon coatings obtained by pulsed Nd: YAG laser deposition on a steel substrate. Surface and Coatings Technology, Vol. 259, 2014, pp. 415-425.

[28] Jongwannasiri, C., S. Yoshida, and S. Watanabe. Effects of fluorine and silicon incorporation on tribological performance of diamond-like carbon films. Materials Sciences and Applications, Vol. 10, 2019, pp. 170-185.

[29] Cemin, F., L. T. Bim, C. M. Menezes, M. E. H. Maia da Costa, I. J. R. Baumvol, F. Alvarez, et al. The influence of different silicon adhesion interlayers on the tribological behavior of DLC thin films deposited on steel by EC-PECVD. Surface and Coatings Technology, Vol. 283, 2015, pp. 115-121.
[30] Sun, L., X. Zuo, P. Guo, X. Li, P. Ke, and A. Wang. Role of deposition temperature on the mechanical and tribological properties of $\mathrm{Cu}$ and $\mathrm{Cr}$ co-doped diamond-like carbon films. Thin Solid Films, Vol. 678, 2019, pp. 16-25.

[31] Rodriguez, B. J., T. L. Schiller, D. Proprentner, M. Walker, C. T. J. Low, B. Shollock, et al. Effect of chromium doping on high temperature tribological properties of silicon-doped diamond-like carbon films. Tribology International, Vol. 152, 2020, id. 106546.

[32] Robertson, J. Diamond-like amorphous carbon. Materials Science and Engineering: R: Reports, Vol. 37, No. 4, 2002, pp. 129-281.

[33] Irmer, G. and A. Dorner-Reisel. Micro-Raman studies on DLC coatings. Advanced Engineering Materials, Vol. 7, 2010, pp. 694-705.

[34] Cui, W. G., Q. B. Lai, L. Zhang, and F. M. Wang. Quantitative measurements of $\mathrm{sp}^{3}$ content in DLC films with Raman spectroscopy. Surface and Coatings Technology, Vol. 205, 2010, pp. 1995-1999.

[35] Ahmad, S. I., H. Hamoudi, A. Abdala, Z. K. Ghouri, and K. M. Youssef. Graphene-reinforced bulk metal matrix composites: Synthesis, microstructure, and properties. Reviews on Advanced Materials Science, Vol. 59, No. 1, 2020, pp. 67-114.

[36] Choi, J. and T. Kato. Self-assembled monolayers on ta-C surfaces: Effect of $\mathrm{sp}^{3} / \mathrm{sp}^{2}$ ratio on adsorption rate and friction. Journal of Applied Physics, Vol. 93, 2003, pp. 8722-8724.

[37] Tang, J. Study on deposition of amorphous hydrogenate DLC films on germanium substrates by RF-PECVD. Proceedings of SPIE - The International Society for Optical Engineering, Vol. 31, 2009, pp. 622-626.

[38] Cho, Y. K., Y. H. Shin, S. H. Jeong, Y. Z. Lee. Tribological behavior of DLC Films by RF-PECVD at the elevated temperature. Key Engineering Materials, Vol. 353-358, 2007, pp. 1781-1784.

[39] Ishikawa, T. and J. Choi. The effect of microstructure on the tribological properties of a-C:H films. Diamond and Related Materials, Vol. 89, 2018, pp. 94-100.

[40] Cashiragi, A. C. and J. Robertson. Raman spectroscopy of hydrogenated amorphous carbon. Physical Review B, Vol. 72, 2005, id. 085401.

[41] Neville, A., A. Morina, T. Haque, and M. Voong. Compatibility between tribological surfaces and lubricant additives - How friction and wear reduction can be controlled by surface/lube synergies. Tribology International, Vol. 40, 2007, pp. 1680-1695.

[42] Arslan, A., H. H. Masjuki, M. Varman, M. A. Kalam, M. M. Quazi, K. A. H. Al Mahmud, et al. Effects of texture diameter and depth on the tribological performance of DLC coating lubricated sliding condition. Applied Surface Science, Vol. 356, 2015, p. 1135-1149.

[43] Arslan, A, H. H. Masjuki, M. Varman, M. A. Kalam, M. M. Quazi, and M. H. Mosarof. Effect of change in temperature on the tribological performance of micro surface textured DLC coating. Journal of Materials Research, Vol. 31, No. 13, 2015, id. 1837.

[44] Xu, W., M. J. Dai, S. S. Lin, H. J. Hou, H. Li, and K. S. Zhou. High temperature tribological behavior of W-doped diamondlike carbon films. Tribology, Vol. 37, 2017, pp. 379-386. 
[45] Yu, W., J. Wang, W. Huang, L. Cui, and L. Wang. Improving high temperature tribological performances of Si doped diamond-like carbon by using $\mathrm{W}$ interlayer. Tribology International, Vol. 146, 2020, id. 106241.

[46] Zhang, J., J. Lou, H. He, Y. Xie, and Y. Xie. Comparative investigation on the tribological performances of TiN, TiCN, and Ti-DLC film-coated stainless steel. Journal of Materials, Vol. 71, 2019, pp. 4872-4879.

[47] Zhang, Y. G, W. C. Sun, Y. R. Dong, M. Ma, Y. W. Liu, S. S. Tian, et al. Electrodeposition and microstructure of $\mathrm{Ni}$ and B co-doped diamond-like carbon (Ni/B-DLC) films. Surface and Coatings Technology, Vol. 405, 2020, id. 126713.

[48] Wu, Q., W. S. Miao, Y. D. Zhang, H. J. Gao, and D. Hui. Mechanical properties of nanomaterials: A review. Nanotechnology Reviews, Vol. 9, No. 1, 2020, pp. 259-273.

[49] Choi, J., K. Ishii, T. Kato, M. Kawaguchi, and W. Lee. Structural and mechanical properties of DLC films prepared by bipolar PBII\&D. Diamond and Related Materials, Vol. 20, 2011, pp. 845-848.

[50] Jongwannasiri, C. Tribological behavior of $\mathrm{O}_{2}$ and $\mathrm{CF}_{4}$ plasma post-treated diamond-like carbon films under dry air and in a high relative humidity environment. Surface and Coatings Technology, Vol. 306, 2016, pp. 200-204.

[51] Deng, X. R., H. Kousaka, T. Tokoroyama, and N. Umehara. Thermal stability and high-temperature tribological properties of a-C:H and Si-DLC deposited by microwave sheath voltage combination plasma. Tribology Online, Vol. 8, 2013, pp. 257-264.

[52] Fenker, M., M. Balzer, H. A. Jehn, H. Kappl, J. J. Lee, K. H. Lee, et al. Improvement of the corrosion resistance of hard wear resistant coatings by intermediate plasma etching or multilayer structure. Surface and Coatings Technology, Vol. 150, 2002, pp. 101-106.

[53] Rangel, R. C. C., M. E. P. Souza, W. H. Schreiner, C. M. A. Freire, E. C. Rangel, and N. C. Cruz. Effect of the fluorination of DLC film on the corrosion protection of aluminum alloy. Surface and Coatings Technology, Vol. 204, 2010, PP. 3022-3028.

[54] Wu, G. S., L. L. Sun, W. Dai, L. X. Song, and A. Y. Wang. Influence of interlayers on corrosion resistance of diamondlike carbon coating on magnesium alloy. Surface and Coatings Technology, Vol. 204, 2010, pp. 2193-2196.

[55] Zhang, R. H., J. Zhao, and Y. Chang. A novel diamond-like carbon film. Surfaces and Interfaces, Vol. 7, 2017, pp. 1-5.

[56] Casero, E., A. M. Parra-Alfambra, M. D. Peti Dominguez, F. Pariente, E. Lorenzo, and C. Alonso. Differentiation between graphene oxide and reduced graphene by electro chemical impedance spectroscopy (EIS). Electrochemistry Communications, Vol. 20, 2012, pp. 63-66.

[57] Li, H., T. Xu, C. Wang, J. Chen, H. Zhou, and H. Liu. Friction behaviors of hydrogenated diamond-like carbon film in different environment sliding against steel ball. Applied Surface Science, Vol. 249, 2005, pp. 257-265.

[58] Cemin, F., L. T. Bim, C. M. Menezes, C. Aguzzoli, M. E. H. Maia da Costa, I. J. R. Baumvol, et al. On the hydrogenated silicon carbide $(\mathrm{SiCx}: \mathrm{H})$ interlayer properties prompting adhesion of hydrogenated amorphous carbon (a-C:H) deposited on steel. Vacuum, Vol. 109, 2014, pp. 180-183.
[59] Donnet, C. and A. Erdemir. Tribology of diamond-lie carbon films: Fundamentals and applications, Springer, New York, 2008.

[60] Bewilogua, K. and D. Hofmann. History of diamond-like carbon films-from first experiments to worldwide applications. Surface and Coatings Technology, Vol. 242, 2014, pp. 214-225.

[61] Wei, C. and C. H. Chen. The effect of thermal and plastic mismatch on stress distribution in diamond like carbon film under different interlayer/substrate system. Diamond and Related Materials, Vol. 17, 2008, pp. 1534-1540.

[62] Tomastik, J., R. Ctvrtlik, T. Ingr, J. Manak, and A. Opletalova. Effect of nitrogen doping and temperature on mechanical durability of silicon carbide thin films. Scientific Reports, Vol. 8, 2018, id. 10428.

[63] Chouquet, C., G. Gerbaud, M. Bardet, S. Barrat, A. Billard, F. Sanchette, et al. Structural and mechanical properties of a-C:H and Si doped a-C:H thin films grown by LF-PECVD. Surface and Coatings Technology, Vol. 204, 2010, pp. 1339-1346.

[64] Yang, W. J., T. Sekino, K. B. Shim, K. Niihara, and K. H. Auh. Deposition and microstructure of Ti-containing diamond-like carbon nano composite films. Thin Solid Films, Vol. 473, 2005, pp. 252-258.

[65] Ong, S. E., S. Zhang, H. J. Du, and D. Sun. Relationship between bonding structure and mechanical properties of amorphous carbon containing silicon. Diamond and Related Materials, Vol. 16, 2007, pp. 1628-1635.

[66] Kulikovsky, V., V. Vorlicek, P. Bohac, A. Kurdyumov, and L. Jastrabik. Mechanical properties of hydrogen-free a-C:Si films. Diamond and Related Materials, Vol. 13, 2004. pp. 1350-1355.

[67] Caschera, D., F. Federici, S. Kaciulis, L. Pandolfi, A. Cusma, and G. Padeletti. Deposition of Ti-containing diamond-like carbon (DLC) films by PECVD technique. Materials Science and Engineering: C, Vol. 27, 2007, pp. 1328-1330.

[68] Voevodin, A., M. Donley, and J. Zabinski. Pulsed laser deposition of diamond-like carbon wear protective coatings: A review. Surface and Coatings Technology, Vol. 92, 1997, pp. 42-49.

[69] Ueng, H. and C. Guo. Diamond-like. carbon coatings on microdrill using an ECR-CVD system. Applied Surface Science, Vol. 249, 2005, pp. 246-256.

[70] Bharathy, P. V., D. Nataraj, P. K. Chu, H. Wang, Q. Yang, $M$. Kiran, et al. Effect of titanium incorporation on the structural, mechanical and biocompatible properties of DLC thin films prepared by reactive-biased target ion beam deposition method. Applied Surface Science, Vol. 257, 2010, pp. 143-150.

[71] Zhang, T. F., B. Gan, S. M. Park, Q. M. Wang, and K. H. Kim. Influence of negative bias voltage and deposition temperature on microstructure and properties of superhard $\mathrm{TiB}_{2}$ coatings deposited by high power impulse magnetron sputtering. Surface and Coatings Technology, Vol. 253, 2014, pp. 115-122.

[72] Zhang, T. F., Q. M. Wang, J. Lee, P. Ke, R. Nowak, and K. H. Kim. Nano crystalline thin films synthesized from a $\mathrm{Ti}_{2}$ AIN compound target by high power impulse magnetron 
sputtering technique. Surface and Coatings Technology, Vol. 212, 2012, pp. 199-206.

[73] Sarakinos, K., A. Braun, C. Zilkens, S. Mraz, J. Schneider, H. Zoubos, et al. Exploring the potential of high power impulse magnetron sputtering for growth of diamond-like carbon films. Surface and Coatings Technology, Vol. 206, 2012, pp. 2706-2710.

[74] Staia, M. H., L. Dubar, M. Dubar, E. S. Puchi-Cabrera, A. Lost, P. de Baets, et al. Mechanical characterization of a prototype a-C:Cr:Si and its tribological behavior at high temperature. Tribology International, Vol. 100, 2016, pp. 242-254.

[75] Banerji, A., S. Bhowmick, and A. T. Alpas. High temperature tribological behavior of $\mathrm{W}$ containing diamond-like carbon (DLC) coating against titanium alloys. Surface and Coatings Technology, Vol. 241, 2014, pp. 93-104.

[76] Salah, N., A. Alshahrie, J. Iqbal, P. M. Z. Hasan, and M. S. Abdel-wahab. Tribological behavior of diamond-like carbon thin films deposited by the pulse laser technique at different substrate temperatures. Tribology International, Vol. 103, 2016, pp. 274-280.

[77] Lee, W. Y., T. Tokoroyama, Y.J. Jang, N Umehara Effect of substrate bias and temperature on friction and wear properties for ta- $C$ coating prepared under different substrate bias voltages with filtered cathodic vacuum arc deposition. Tribology Online, Vol. 13, 2018, pp. 241-247.

[78] Huheey, J. E., E. A. Keiter, and R. L. Keiter. Inorganic chemistry: Principles of structure and reactivity. Journal of Chemical Education, Vol. 70, 1993, id. 70.

[79] Li, H., T. Xu, C. Wang, J. Chen, H. Zhou, and H. Liu. Frictioninduced physical and chemical interactions among diamondlike carbon films, steel ball and water and/or oxygen molecules. Diamond and Related Materials, Vol. 15, 2006, pp. 1228-1234.

[80] Sheeja, D., B. K. Tay, S. P. Lau, and X. Shi. Tribological properties and adhesive strength of DLC coatings prepared under different substrate bias voltages. Wear, Vol. 249, 2001, pp. 433-439.

[81] Li, F., S. Zhang, J. Kong, Y. Zhang, and W. Zhang. Multilayer DLC coatings via alternating bias during magnetron sputtering. Thin Solid Film, Vol. 519, 2011, pp. 4910-4916.

[82] Li, C., L. Huang, and J. Yuan. Effect of $\mathrm{sp}^{3}$ content on adhesion and tribological properties of non-hydrogenated DLC films. Materials, Vol. 13, 2020, id. 1911.

[83] Miyake, S., S. Suzuki, and M. Miyake. Friction durability of extremely thin diamond-like carbon films at high temperature. Materials, Vol. 10, 2017, id. 159.

[84] Ding, Q., L. Wang, Y. Wang, S. C. Wang, L. Hu, and Q. Xue. Improved tribological behavior of DLC films under water lubrication by surface texturing. Tribology Letters, Vol. 41, 2011, pp. 439-449.

[85] Kalin, M., E. Roman, L. Ožbolt, and J. Vižintin. Metal-doped (Ti, WC) diamond-like-carbon coatings: Reactions with extreme-pressure oil additives under tribological and static conditions. Thin Solid Films, Vol. 518, 2010, pp. 4336-4344.

[86] Mistry, K. K., A. Morina, and A. Neville. A tribo chemical evaluation of a WC-DLC coating in EP lubrication conditions. Wear, Vol. 271, 2011, pp. 1739-1744.
[87] Equey, S., S. Roos, U. Mueller, R. Hauert, N. D. Spencer, and R. Crockett. Tribofilm formation from ZnDTP on diamond-like carbon. Wear, Vol. 264, 2008, pp. 316-321.

[88] Podgornik, B., S. Jacobson, and S. Hogmark. DLC coating of boundary lubricated components advantages of coating one of the contact surfaces rather than both or none. Tribology International, Vol. 36, 2003, pp. 843-849.

[89] Lawes, S. D. A., M. E. Fitzpatrick, and S. V. Hainsworth. Evaluation of the tribological properties of DLC for engine applications. Journal of Physics D: Applied Physics, Vol. 40, 2007, pp. 5427-5437.

[90] Tani, H., R. Naito, R. Lu, S. Koganezawa, and N. Tagawa. Low friction of diamond-like carbon film due to liquid hydro carbon generated by laser heating in a nitrogen gas environment. Tribology Letters, Vol. 68, 88, 2020.

[91] Al Mahmud, K. A. H., M. Varman, M. A. Kalam, H. H. Masjuki, H. M. Mobarak, and N. W. M. Zulkifli. Tribological characteristics of amorphous hydrogenated $(\mathrm{a}-\mathrm{C}: \mathrm{H})$ and tetrahedral (ta-C) diamond-like carbon coating at different test temperatures in the presence of commercial lubricating oil. Surface and Coatings Technology, Vol. 245, 2014, pp. 133-147.

[92] Evaristo, M., R. Azevedo, C. Palacio, and A. Cavaleiro. Influence of the silicon and oxygen content on the properties of non-hydrogenated amorphous carbon coatings. Diamond and Related Materials, Vol. 70, 2016, pp. 201-210.

[93] Hatada, R., S. Flege, K. Baba, W. Ensinger, H. J. Kleebe, I. Sethmann, et al. Temperature dependent properties of silicon containing diamondlike carbon films prepared by plasma source ion implantation. Journal of Applied Physics, Vol. 107, 2010, id. 083307.

[94] Oguri, K. and T. Arai. Tribological properties and characterization of diamond-like carbon coatings with silicon prepared by plasma-assisted chemical vapour deposition. Surface and Coatings Technology, Vol. 47, 1991, pp. 710-21.

[95] Oguri, K. and T. A. Rai. Two different low friction mechanisms of diamond-like carbon with silicon coatings formed by plasma-assisted chemical vapor deposition. Journal of Materials Research, Vol. 7, 1992, pp. 1313-1316.

[96] Yang, B., Y. Zheng, B. Zhang, L. Wei, and J. Zhang. The hightemperature tribological properties of Si-DLC films. Surface and Interface Analysis, Vol. 44, 2012, pp. 1601-1605.

[97] Bhowmick, S., A. Banerji, M. J. Lukitsch, and A. T. Alpas. The high temperature tribological behavior of $\mathrm{Si}, \mathrm{O}$ containing hydrogenated diamond-like carbon (a-C:H/a-Si:O) coating against an aluminum alloy. Wear, Vol. 330-331, 2015, pp. 261-271.

[98] Jantschner, O., S. K. Field, D. Holec, A. Fian, D. Music, J. M. Schneider, et al. Origin of temperature-induced low friction of sputtered Si-containing amorphous carbon coatings. Acta Materialia, Vol. 82, 2015, pp. 437-446.

[99] Savchenko, D., V. Vorlicek, A. Prokhorov, E. Kalabukhova, J. Lancok, and M. Jelinek. Raman and EPR spectroscopic studies of chromium-doped diamond-like carbon films. Diamond and Related Materials, Vol. 83, 2018, pp. 30-37.

[100] Yang, S. and D. G. Teer. Investigation of sputtered carbon and carbon/chromium multi-layered coatings. Surface and Coatings Technology, Vol. 131, 2000, pp. 412-416.

[101] Yang, S., X. Li, N. M. Renevier, and D. G. Teer. Tribological properties and wear mechanism of sputtered $\mathrm{C} / \mathrm{Cr}$ coating. 
Surface and Coatings Technology, Vol. 142-144, 2001, pp. 85-93.

[102] Fu, Z., C. Wang, W. Zhang, W. Wang, W. Yue, X. Yu, et al. Influence of $W$ content on tribological performance of W-doped diamond-like carbon coatings under dry friction and polyalpha olefin lubrication conditions. Materials and Design, Vol. 51, 2013, pp. 775-779.

[103] Bhowmick, S., A. Banerji, and A. T. Alpas. Tribological behaviour of W-DLC against an aluminium alloy subjected to lubricated sliding. Tribology in Industry, Vol. 37, 2015, pp. 277-283.

[104] Gharam, A. A., M. J. Lukitsch, M. P. Balogh, N. Irish, and A. T. Alpas. High temperature tribological behavior of W-DLC against aluminum. Surface and Coatings Technology, Vol. 206, 2011, pp. 1905-1912.

[105] Santiago, J. A., I. Fernández-Martínez, J. C. Sánchez-López, T. C. Rojas, A. Wennberg, V. Bellido-González, et al. Tribomechanical properties of hard $\mathrm{Cr}$-doped DLC coatings deposited by low-frequency HiPIMS. Surface and Coatings Technology, Vol. 382, 2019, id. 124899.

[106] Li, Q., K. X. Gao, L. F. Zhang, J. Wang, B. Zhang, and J. Y. Zhang. Further improving the mechanical and tribological properties of low content Ti-doped DLC film by W incorporating. Applied Surface Science, Vol. 353, 2015, pp. 522-529.

[107] Zhang, S., W. Yue, J. Kang, Y. Wang, Z. Fu, L. Zhu, et al. Ti content on the tribological properties of W/Ti-doped diamond-like carbon film lubricating with additives. Wear, Vol. 430-431, 2019, pp. 137-144.

[108] Zhang, C., H. Liu, Y. Zhou, J. Li, Y. Sun, Y. Wang, et al. The effect of high temperature heat treatment on the tribological property of a carbon fiber/pyrolytic carbon/silicon carbide composite using polycarbosilane. Ceramics International, Vol. 46, 2020, pp. 4493-4501.

[109] Kim, D. W. and K. W. Kim. Effects of sliding velocity and ambient temperature on the friction and wear of a boundarylubricated, multi-layered DLC coating. Wear, Vol. 315, 2014, pp. 95-102.

[110] Roy, R. K. and K. R. Lee. Biomedical applications of diamondlike carbon coatings: A review. Journal of Biomedical Materials Research - Part B: Applied Biomaterials, Vol. 83B, 2010, pp. 72-84.

[111] Kosla, K., M. Olejnik, and K. Olszewska. Preparation and properties of composite materials containing graphene structures and their applicability in personal protective equipment: A review. Reviews on Advanced Materials Science, Vol. 59, 2020, pp. 215-242.

[112] Nakonieczny, D. S., M. Antonowicz, and Z. K. Paszenda. Cenospheres and their application advantages in biomedical engineering - a systematic review. Reviews on Advanced Materials Science, Vol. 59, No. 1, 2020, pp. 115-130.

[113] Zhang, L., T. Liu, Y. H. Xie, Z. Zeng, and J. Y. Chen. A new classification method of nanotechnology for design integration in biomaterials. Nanotechnology Reviews, Vol. 9, No. 1, 2020, pp. 820-832.

[114] Bayón, R., A. Igartua, J. J. González, and U. Ruiz de Gopegui. Influence of the carbon content on the corrosion and tribocorrosion performance of Ti-DLC coatings for biomedical alloys. Tribology International, Vol. 88, 2015, pp. 115-125.

[115] Schroeder, A., G. Francz, A. Bruinink, R. Hauert, J. Mayer, and E. Wintermantel. Titanium containing amorphous hydrogenated carbon films (a-C:H/Ti): Surface analysis and evaluation of cellular reactions using bone marrow cell cultures in vitro. Biomaterials, Vol. 21, 2000, pp. 449-456.

[116] Bociaga, D., P. Komorowski, D. Batory, W. Szymanski, A. Olejnik, K. Jastrzebski, et al. Silver-doped nanocomposite carbon coatings (Ag-DLC) for biomedical applicationsPhysiochemical and biological evaluation. Applied Surface Science, Vol. 355, 2015, pp. 388-397.

[117] Bewilogua, K., J. Brand, H. Thomsen, M. Weber, and R. Wittorf. Structure, properties and applications of diamond-like carbon coatings prepared by reactive magnetron sputtering. Zeitschrift für Metallkunde, Vol. 96, 2005, pp. 998-1004.

[118] Zin, M. R. B., Y. Yagi, K. Sasaki, N. Inayoshi, T. Tokoroyama, $\mathrm{N}$. Umehara, et al. The effects of temperature, pressure and dissolved oxygen concentration (DO) in water on the wear of the hydrogenated diamond-like carbon (HDLC) at high temperature and pressurized water. Tribology International, Vol. 109, 2017, pp. 48-57.

[119] Ohana, T., M. Suzuki, T. Nakamura, A. Tanaka, and Y. Koga. Low-friction behaviour of diamond-like carbon films in a water environment. Diamond and Related Materials, Vol. 15, No. 4-8, 2006, pp. 962-966.

[120] Fraga, M. A., H. Furlan, R. S. Pessoa, L. A. Rasia, and C. F. R. Mateus. Studies on $\mathrm{SiC}, \mathrm{DLC}$ and $\mathrm{TiO}_{2}$ thin films as piezoresistive sensor materials for high temperature application. Microsystem Technologies, Vol. 18, No. 7-8, 2012, pp. 1027-1033.

[121] Jahanmir, S., H. Heshmat, and C. Heshmat. Evaluation of DLC coatings for high-temperature foil bearing applications. Journal of Tribology, Vol. 131, No. 1, 2009, pp. 5-7.

[122] Bewilogua, K. and D. Hofmann. History of diamond-like carbon films-from first experiments to worldwide applications. Surface and Coatings Technology, Vol. 242, 2014, pp. 214-225. 